\title{
Mechanism and Control of Rockburst Induced by Draining Spatial Islands and Squaring
}

\author{
Yunhai Cheng $\mathbb{D}^{1,2,3}$ Fenghui Li $\mathbb{D}^{2,3}$ Xiufeng Zhang, ${ }^{4}$ Gangwei Li, ${ }^{1,2}$ and Le Xu ${ }^{5}$ \\ ${ }^{1}$ National Engineering Laboratory of Coalmine Backfilling Mining, Shandong University of Science and Technology, \\ Taian 271000, China \\ ${ }^{2}$ State Key Laboratory of Mining-Induced Response and Disaster Prevention and Control in Deep Coal Mines, \\ Anhui University of Science and Technology, Huainan 232000, China \\ ${ }^{3}$ School of Mining Engineering, Anhui University of Science and Technology, Huainan 232000, China \\ ${ }^{4}$ Coal Burst Prevention and Control Research Centre, Yankuang Group Co., Ltd., Zoucheng 273500, China \\ ${ }^{5}$ Chahasu Coal Mine, Inner Mongolia Energy Co., Ltd., Inner Mongolia, Ordos 017000, China
}

Correspondence should be addressed to Fenghui Li; ahlifenghui@163.com

Received 18 September 2021; Revised 16 December 2021; Accepted 28 January 2022; Published 28 February 2022

Academic Editor: Mohammed Fattah

Copyright (C) 2022 Yunhai Cheng et al. This is an open access article distributed under the Creative Commons Attribution License, which permits unrestricted use, distribution, and reproduction in any medium, provided the original work is properly cited.

\begin{abstract}
A small-pillar gob-side roadway showed rockburst appearance during the mining of a gob-side working face located in the Shaanxi-Inner Mongolia mining area. This study examines the 2202 gob-side working face of a coal mine in Inner Mongolia as a case study. A stress evolution model was built for the static-stress spatial islands formed by drainage regions and goafs based on the spatial relationships between drainage regions and goafs. The average microseismic frequency and energy of the high-stress zone of spatial islands were at least 1.37 times of those of other zones, validating the presence of spatial islands. The dynamic and static load effects of working face squaring were obtained based on the evolution of the stope roof as well as changes in microseismic data. Microseismically active zones were advanced to $200 \mathrm{~m}-300 \mathrm{~m}$ on working faces. The rockbursts induced by high static loads and dynamic and static loads formed by spatial islands and squaring were calculated. According to calculation results, the critical stress concentration value under high static loads was 3.27; the critical static stress concentration value under dynamic and static loads was 1.81. The superposition of drainage boundary stress, goaf lateral stress, and lead stress might reach the critical stress concentration under dynamic load disturbances, causing rockbursts. A stress adjustment scheme was established, including overall hydraulic fracturing of the external roof of the drainage region, reduction of stoping speed, and pressure relief of largediameter boreholes. The stress adjustment scheme was implemented on-site and supplemented by monitoring and early warning methods to safely advance by the first squaring region.
\end{abstract}

\section{Introduction}

Rockbursts are one of the most serious dynamic disasters threatening coal mine safety. Existing studies have shown that the primary factors influencing the occurrence of rockbursts include geological factors (such as faults, folds, hard roofs (squared), coal seam attitude, and coal mass properties) as well as mining design factors (such as pillars, working face shapes, and island working faces) [1-14].

In this study, rockburst manifestations were primarily related to working face squaring and spatial island working faces, so we primarily collected and sorted through existing data related to both spatial island working faces and squaring. Cao et al. [15] theoretically examined how the spatial structure and rupture movement of thick and hard overburden of island working faces would affect mine earthquake activities. They held that the large-scale rupture movement of the key strata of a working faces" "T"-shaped overburden space structure was the primary force source of mine earthquake activities as well as provided densified borehole pressure relief in the primary squaring, second squaring, and third squaring regions of working faces. By combining the overburden space structure and mine pressure, Jiang et al. [16] investigated the overburden movement 
laws of the "103 upper 02 asymmetric island fully mechanized working face" of the Baodian Coal Mine, explored the prediction method for "hard rock fracture-type" mine earthquakes, and identified the "squaring" region of a working face as its primary rockburst hazard region.

Island working faces are generally classified as either plane island working faces (formed by goafs on the two sides of the same coal seam) or spatial island working faces (formed by goafs on the two sides of different coal seams, formed by faults and goafs, or formed by drainage regions and goafs (under investigation in this study)). Many experts and scholars have extensively studied spatial island working faces (formed by two goafs of different coal seams or formed by faults and goafs). Yang et al. [17] proposed putting the rockbursts of island working faces under "classified control" and classified island working faces into six types, that is, island working faces with critical extraction on both sides, island working faces with subcritical extraction on both sides, island working faces with critical extraction on one side, and subcritical extraction on the other side, stereoscopic island working faces formed by goafs of different coal seams, hidden island working faces formed by geological structures, and composite island working faces formed by a geological structure-goaf. Cao et al. [18] examined the dynamic load mechanism of fault slip in the rockburst appearance of an island working face adjacent to a fault on one side and a goaf on the other side and performed a CT-based back analysis on the rockburst hazard of a working face with dynamic early warning. Zhu et al. [19] studied the overall instability type of rockburst in a quasi-island working face formed by fault cutting. Wang et al. [20] investigated the mine pressure manifestations of the 220 quasi-island working face formed by mining of the 3-2 and 4-2 diverged/ converged working section of Xiashijie Coal Mine in Tongchuan, finding that the dynamic pressure manifestation of the working face was closely related to periodic weighting and roof activities.

The above scholars have extensively studied island working faces formed by faults and goafs as well as those formed by goafs of different coal seams. This study primarily investigated a type of novel static-stress spatial islands formed by roof drainage regions and goafs. These spatial islands were formed by drainage stress transfer and goaf lateral stress transfer in the sandstone aquifers of the Yan'an Formation and the Zhiluo Formation. The erratic stress anomaly regions formed inside working faces inevitably affect production safety. In particular, the coupling of stress anomaly regions and working face squaring regions produced abnormal pressure manifestations on the gob side of the coupling region. This is an issue worthy of further research. With regard to the obvious dynamic phenomena occurring on the gob side of a spatial island working face, the formation and stress evolution process of the spatial island working face were explored using theoretical analysis as well as on-site monitoring. The force sources behind its rockburst appearance were also analyzed. The mechanism of rockburst induced by high static loads and by dynamic and static loads under the combined action of spatial islands and working face squaring was clarified, and control measures were prepared.

\section{Engineering Background}

When the 2202 gob-side working face of a coal mine in the Shaanxi-Inner Mongolia mining area was advanced to $200 \mathrm{~m}-300 \mathrm{~m}$, the gob-side gate road of the working face experienced frequent coal burst and ejection phenomena as well as abnormal pressure manifestations in the yellow area in Figure 1. The 2202 working face had a burial depth of $731.4 \mathrm{~m}$, a dip angle of $0-4$, and a coal mass strength of 13.3 MPa and was characterized by simple coal seam structure and small relief. The effects of geological structures (such as faults and folds) were not detected. Table 1 provides the composite columnar section of the 2202 working face. The space above the 2-2 coal seam contains alternating sandy mudstone and medium sandstone. The relative water-rich anomaly regions of the Yan'an Formation and the Zhiluo Formation occur in the roof. The area filled by the red transverse lines is the relative water-rich anomaly region of the Yan'an Formation, $6.87 \mathrm{~m}$ away from the 2-2 coal seam. The area filled by the green transverse lines is the relative water-rich anomaly region of the Zhiluo Formation, $58.34 \mathrm{~m}$ away from the 2-2 coal seam.

\section{Mechanism of Rockburst Induced by Spatial Islands}

Island working faces are generally formed by goafs on the two sides caused by production continuity problems. Pillartype islands are also present and are the result of pillar recycling. As for the spatial islands formed in the 2202 working face in this study, on the one side, there were goafs formed after mining of the 2201 working face. On the other side, there were goaf-like stress transfer regions formed by the relative water-rich anomaly regions of the roof after dewatering, such as 1\# and 3\# spatial islands in Figure 2. In addition, some spatial islands were formed by drainage regions alone, such as 2\# spatial island in Figure 2.

1\# spatial island was formed by drainage regions (primarily the drainage region of the Yan'an Formation) and goafs. After dewatering of the sandstone water-rich region of the Yan'an Formation, the support of the upper strata was weakened, and the upper strata settled and deformed. The stress transferred towards the drainage region boundary and superposed with goaf lateral stress, resulting in a unimodal stress distribution. Depending on the effect of the drainage region of the Zhiluo Formation on 1\# spatial island, 1\# spatial island was divided into two zones, i.e., zone 1 and zone 2 . Zone 1 was located below the drainage region of the Zhiluo Formation. The decline in coal seam stress in the drainage region of the Zhiluo Formation lowered the stress level of the spatial island, as illustrated by the profile in Figure 3. Zone 2 was located outside the drainage region of the Zhiluo Formation and raised the stress level of the island working face, as illustrated by the profile in Figure 4 .

2\# spatial island was formed by the sandstone water-rich region of the Yan'an Formation after dewatering; however, the entire spatial island working face was located below the drainage region of the Zhiluo Formation. As shown in Figure 5, the mine pressure manifestations of the spatial 


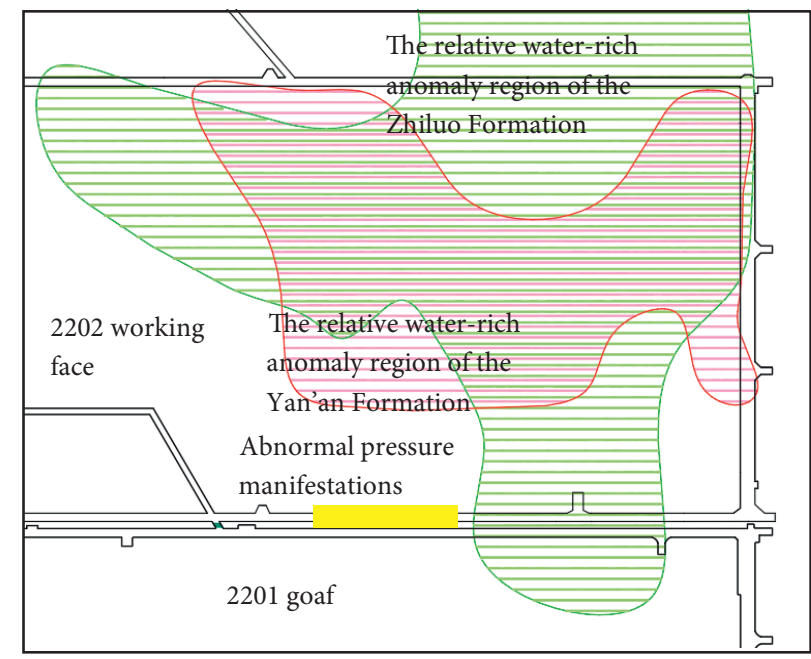

Figure 1: Spatial relationships and rockburst appearance of working faces.

TABle 1: Composite columnar section of the 2202 working face.

\begin{tabular}{lcc}
\hline Strata & Thickness $(\mathrm{m})$ & Comment \\
\hline Medium fine sandstone & 12.91 & The relative water-rich anomaly region of the Zhiluo Formation \\
Sandy mudstone & 12.45 & \\
Medium fine sandstone & 13.56 & \\
Sandy mudstone & 13.90 & The relative water-rich anomaly region of the Yan'an Formation \\
Medium fine sandstone & 11.56 & \\
Sandy mudstone & 6.87 & \\
$2-2$ coal seam & 6.50 & \\
\hline
\end{tabular}

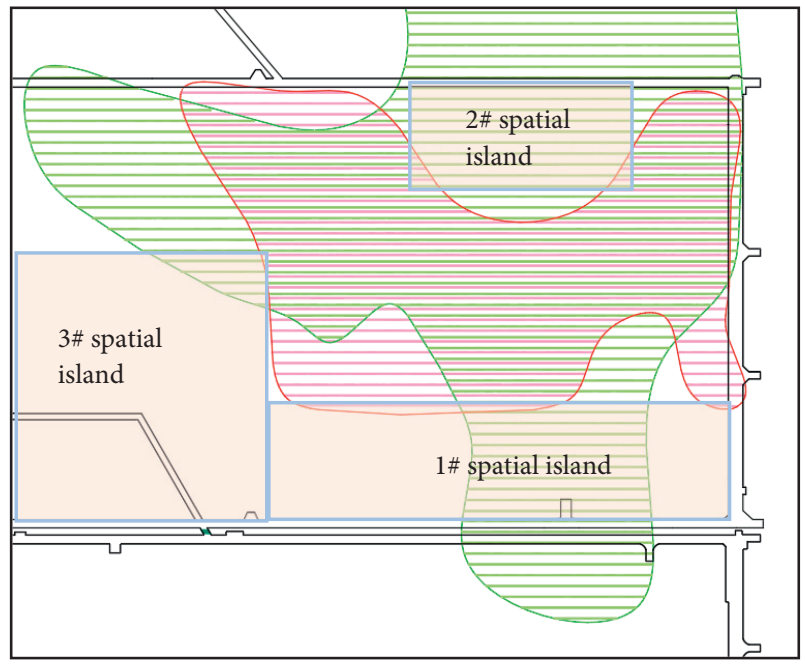

FIgURE 2: Distribution of spatial island working faces after dewatering.

island, affected by interactions between the sandstone drainage regions of the Yan'an and Zhiluo Formations, were weak.

$3 \#$ spatial island was formed by the drainage region of the Zhiluo Formation and goafs. The drainage stress transfer of the sandstone water-rich region of the Zhiluo Formation superposed with goaf lateral stress, resulting in bimodal stress distribution as shown in Figure 6. The stress concentration level of $3 \#$ spatial island was lower than that of $1 \#$

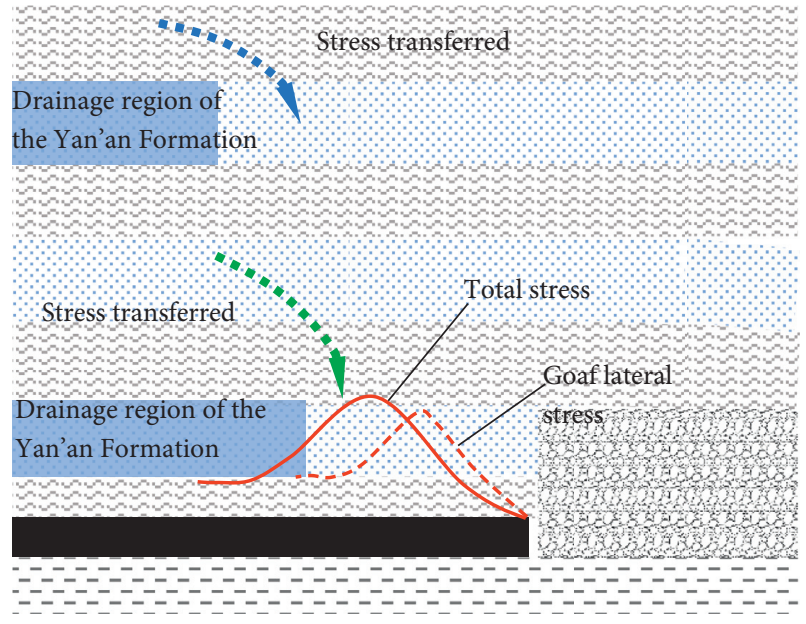

FIGURE 3: Stress distribution of zone 1 of 1 \# spatial island.

spatial island. 3\# spatial island was formed by the drainage region of the Zhiluo Formation and goafs. The drainage stress transfer of the sandstone water-rich region of the Zhiluo Formation superposed with goaf lateral stress, resulting in bimodal stress distribution. The stress concentration level of $3 \#$ spatial island was lower than that of $1 \#$ spatial island.

The breakage degree of coal-rock mass is related to stress level, and coal-rock mass breakage produces microseismic phenomena. Thus, microseismic energy and frequency can satisfactorily reflect the stress concentration level of coal-rock 


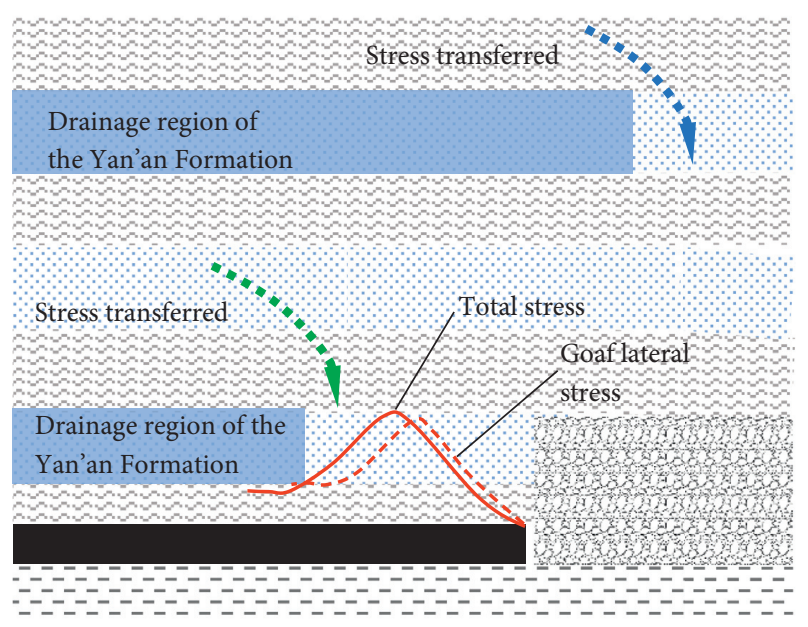

FIgURE 4: Stress distribution of zone 2 of 1 \# spatial island.

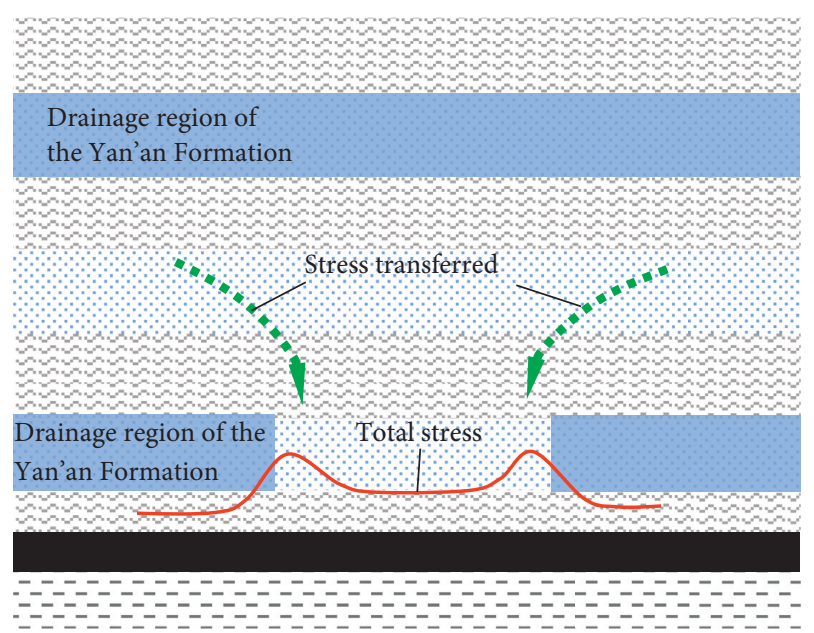

FIGURE 5: Stress distribution of 2\# spatial island.

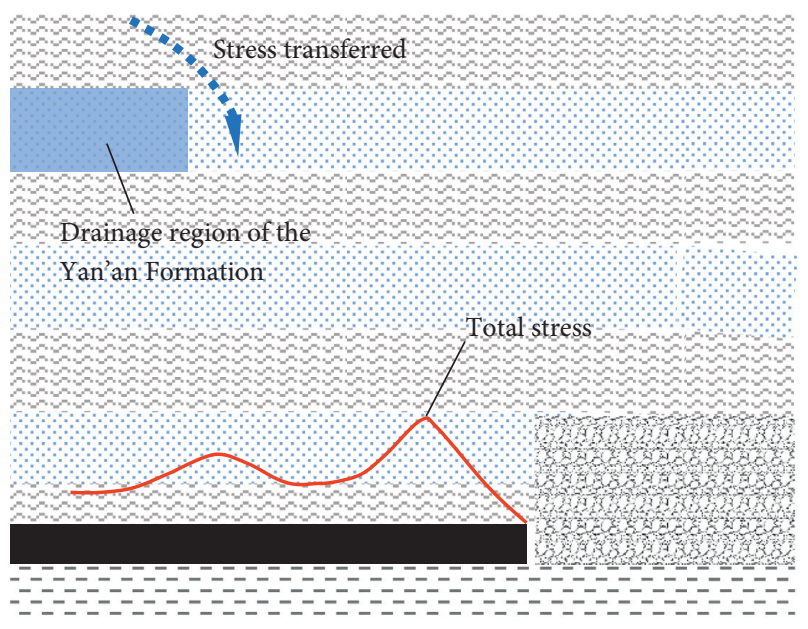

FIgURE 6: Stress distribution of 3\# spatial island.

masses. That is, the higher the energy and frequency of microseismic events, the higher the stress concentration level within a coal-rock mass [21]. In this study, the presence of spatial island working faces was validated using "SOS" microseismic monitoring system software monitoring data. All microseismic events from the 2202 working face occurring over cumulative footage of $487 \mathrm{~m}$ were collected. Events with an energy level of above 10E3 were screened and projected onto the layout plan of the working face. Figure 7 shows the distribution of microseismic events.

The distribution of microseismic events satisfactorily reflects the stress concentration levels of different regions of the working face. Theoretical analysis in this study revealed that $1 \#$ spatial island region had a high-stress concentration level as well as a significant concentration of microseismic events.

1\# spatial island region was divided into three zones, that is, zone 1 , zone 2 , and zone 3 . Zone 2 was located below the drainage region of the Zhiluo Formation. Considering the wide scope of 3\# spatial island, a zone in 3\# spatial island with the same width as $1 \#$ spatial island was selected as zone 4 to avoid the effect of goaf distance. The microseismic data (see Figure 8) from the beginning of the 2202 working face to the working face position in Figure 8 were selected. Zone 5 was enclosed by the line from the open-off cut to the working face position in Figure 8 as well as by the two roadways of the working face.

The average frequency of a zone was defined as the ratio of the total microseismic frequency of the zone to its total area, and the average energy of a zone was defined as the ratio of the total microseismic energy of the zone to its total area (the two special events with an energy level of 10E6 were excluded in statistics), as provided in Table 2.

The average frequencies of zones 2 and 3 were 2.04-2.41 times of those of other zones. The average energies of zones 2 and 3 were 1.37-2.04 times of those of other zones. These results validated the presence of $1 \#$ spatial island. Zones 4 and 5 had similar average frequencies and average energies, which verified the conclusion that the stress transferred from the drainage region of the Zhiluo Formation was not intensified by superposition with 2201 goaf lateral stress. The average frequency and average energy of zone 2 were 0.92 and 0.78 times of those of zone 3 , respectively, which confirmed the protective effect of the drainage region of the Zhiluo Formation for its underlying spatial islands.

\section{Mechanism of Rockburst Induced by Squaring Effect}

Starting with the open-off cut, goaf area increased linearly as the working face advanced. The squaring position was the dividing line marking the transition from short edge change to long edge change for the goaf. Before squaring, the two long edges of the goaf remained constant, while its two short edges continuously increased. Upon squaring, the short and long edges became equal in length. After squaring, the two short edges of the goaf remained constant, while its two long edges continuously increased. The roof stratum of the coal seam can be regarded as a constantly changing rectangular plate. In this case, identifying the distribution pattern of a coal mass stress under the action of the rectangular plate is of vital significance for clarifying the essence of the dynamic pressure of working face squaring as well as understanding 


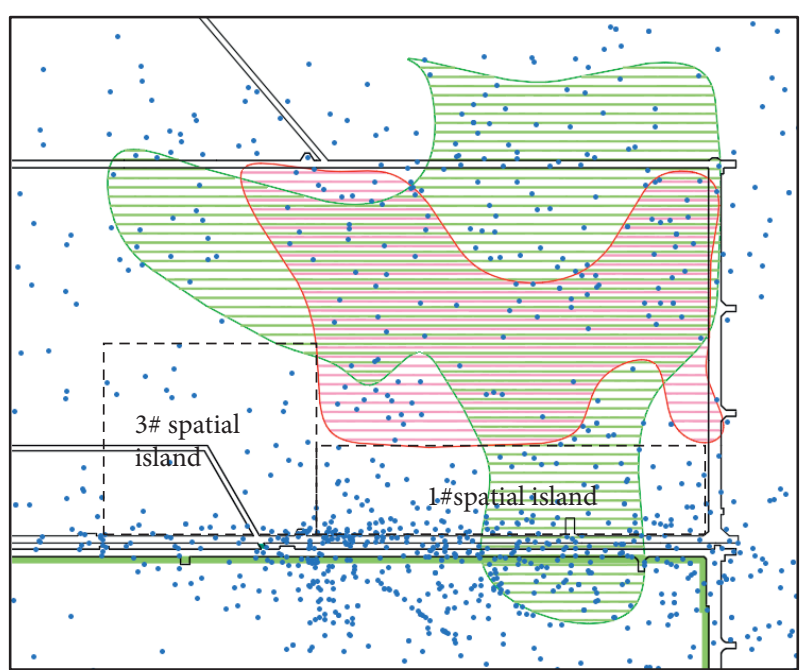

Figure 7: Distribution of microseismic events.

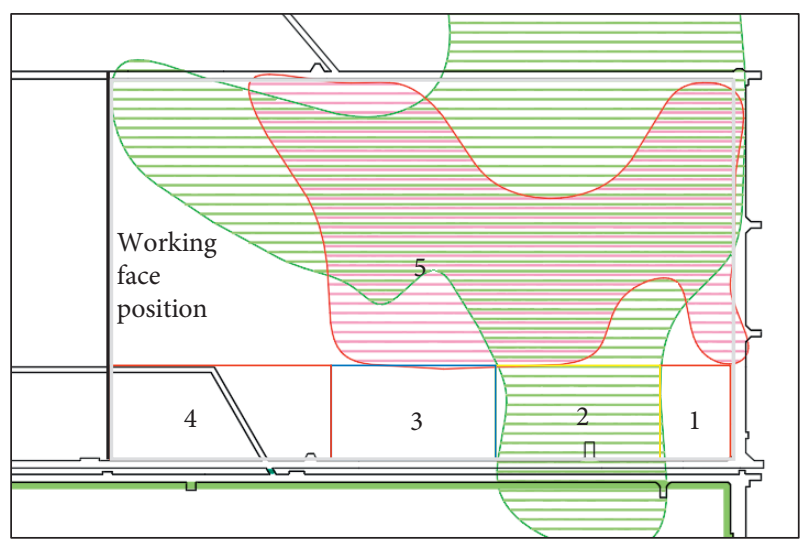

FIGURE 8: Statistical zoning of microseismic data of spatial islands.

TABle 2: Average frequency and energy of each zone.

\begin{tabular}{lcc}
\hline Zone & $\begin{array}{c}\text { Average frequency } \\
\left(\text { event count } / 1000 \mathrm{~m}^{2}\right)\end{array}$ & Average energy $\left(\mathrm{J} / \mathrm{m}^{2}\right)$ \\
\hline 1 & 7.34 & 21.51 \\
2 & 15.36 & 29.88 \\
3 & 16.77 & 38.46 \\
4 & 6.94 & 21.80 \\
5 & 7.52 & 18.82 \\
\hline
\end{tabular}

in depth the effect of overburden space structure on the evolution of coal mass stress.

For a rectangular stope, the advance distance and length of the working face are assumed to be $a$ and $b$, respectively. According to existing studies [22-24], before squaring $(a<b)$, the bending moment distribution, coal mass plastic zone, and coal mass stress of the roof rectangular plate all indicate that the long edges of the rectangular plate have a relatively large moment load bearing capacity. The lead abutment stress of the working face increases with its advance.

When advance distance is equal to the length of the working face $(a=b)$ [25], the working face was in the squaring stage, and $\sigma_{\mathrm{Z}}$ reaches its maximum value as shown in Figure 9. Theoretically, the abutment pressure of the stope is highest when the working face advances to "squaring." Clearly, working face squaring commonly produces stress anomaly regions, which can easily trigger the occurrence of rockbursts.

The squaring stage is the formation stage of stope overburden space structure, and the gob-side working face produces an "S"-shaped stope overburden space structure. The initial fracture of high-level strata produces dynamic loads, which commonly causes dynamic disasters in coal seams $[27,28]$.

When the 2202 working face advanced to $210 \mathrm{~m}$ without any significant change in mining velocity, microseismic event count and maximum energy increased rapidly, so the 2202 working face produced a significant squaring effect, using "origin" analysis software to make Figure 10.

\section{Mechanism of Rockburst Induced by Spatial Islands and Squaring}

5.1. Mechanism of Rockburst Induced by Static Stress. High static load stress is the stress path that leads to the occurrence of rockburst. When the static load reaches the critical rockburst load (i.e., when the static load exceeds 1.5 times of the comprehensive compressive strength of the coal mass), a high rockburst hazard occurs $[29,30]$.

$$
I_{c}=\frac{\sigma}{\bar{\mu}\left[\sigma_{c}\right]} \geq 1.5,
$$

where $\bar{\mu}$ is the average comprehensive compressive coefficient of the coal mass, set as $1-5 ;\left(\sigma_{c}\right)$ is the uniaxial compressive strength of the coal mass.

The 2202 working face had a burial depth of $731.4 \mathrm{~m}$ and a gravity stress of

$$
\sigma_{z}=\gamma H=\frac{2.5 \mathrm{MPa}}{100 \mathrm{~m} \times 731.4 \mathrm{~m}}=18.285 \mathrm{MPa},
$$

where $\sigma_{z}$ is the gravity stress; $\gamma$ is the stress gradient, set as $2.5 \mathrm{MPa} / 100 \mathrm{~m}$; and $H$ is the burial depth of the working face.

The $1 \#$ spatial island region demarcated in the 2202 working face is affected by lead abutment pressure, 2201 goaf lateral pressure, drainage boost region, and squaring-induced static load increase. The static load $\sigma_{j}$ of the coal mass can be calculated using the following formula:

$$
\begin{aligned}
\sigma_{j} & =k \sigma_{z}, \\
& \alpha+\beta(\text { or } \lambda)+v \leq k \leq \alpha+\beta+\lambda+v,
\end{aligned}
$$

where $k$ is the static load concentration coefficient of $1 \#$ spatial island; $\alpha$ is the lead abutment pressure concentration coefficient; $\beta$ is the lateral pressure concentration coefficient of the 2201 goaf; $\lambda$ is the stress concentration coefficient of the drainage boost region; and $v$ is the squaring-induced static load concentration coefficient.

The average comprehensive compressive coefficient $\bar{\mu}$ of the coal mass ranges from 1 to 5 and is set as 1 in the vicinity of roadway surface as well as 3-5 in three-dimensional stress 


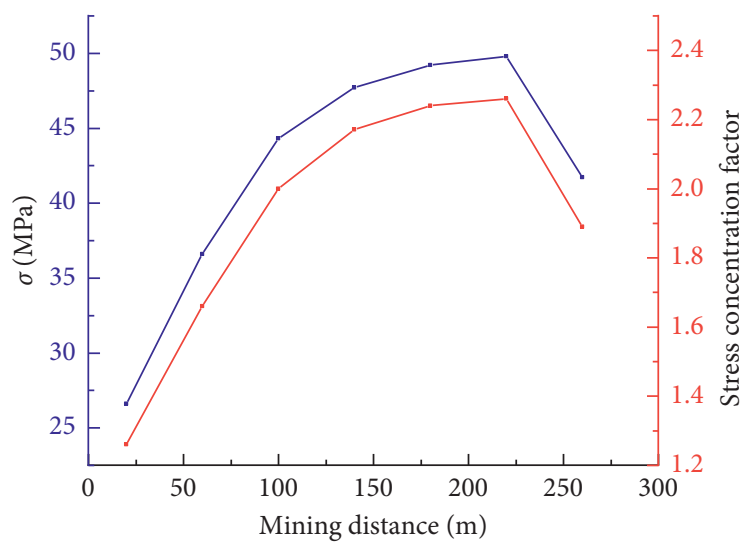

FIGURE 9: Relationship between advance distance and lead abutment pressure [26].

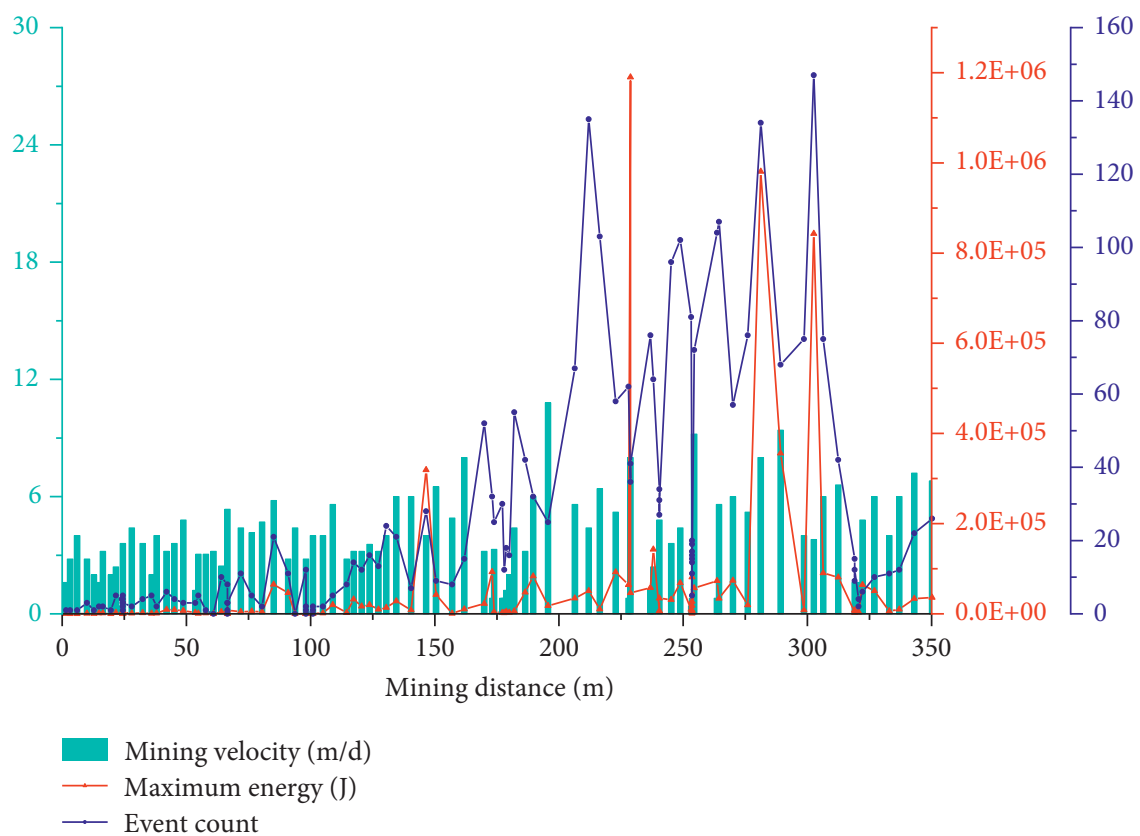

FIgURE 10: Microseismic energy, event count, and mining velocity curves of the 2202 working face.

state. In this study, $1 \#$ spatial island region was $75 \mathrm{~m}$ in width, and the width of pressure relief was $20 \mathrm{~m} . \bar{\mu}$ was set as 3 .

When the static load is equal to or greater than 1.5 times the comprehensive compressive strength of the coal mass, $1 \#$ spatial island working face may experience a static load rockburst; that is,

$$
k \geq \frac{1.5 \bar{\mu}\left[\sigma_{c}\right]}{\sigma_{z}} \approx 3.27,
$$

and when the superposed sum of the stress concentration coefficients of the lead abutment pressure, 2201 goaf lateral pressure, drainage boost region, and squaring-induced static load increase is equal to or greater than 3.27, spatial island regions may experience static load rockburst.

\subsection{Mechanism of Rockburst Induced by Dynamic and Static} Loads. When the superposed sum is less than 3.27 , the critical static load for rockburst is not reached. When the dynamic load produced by the initial fracture of high-level overburden is transferred to the coal mass, a rockburst may be triggered.

Related studies have revealed that rockbursts are triggered by mine earthquakes or blasting under highly concentrated loads, that is, by superposition of dynamic and static loads [31-35], as expressed by the following formula:

$$
\sigma_{j}+\sigma_{d} \geq \sigma_{b}
$$

where $\sigma_{j}$ is the static load on the coal-rock mass; $\sigma_{d}$ is the dynamic load produced by mine earthquakes or blasting; and $\sigma_{b}$ is the ultimate load in case of a rockburst.

The deep coal mass of the working face exists in a triaxial stress state. The comprehensive compressive strength of deep coal mass is far greater than that of roadway surface coal mass, and the critical rockburst load of deep coal mass is also far greater than that of roadway surface coal mass (see Figure 11). 


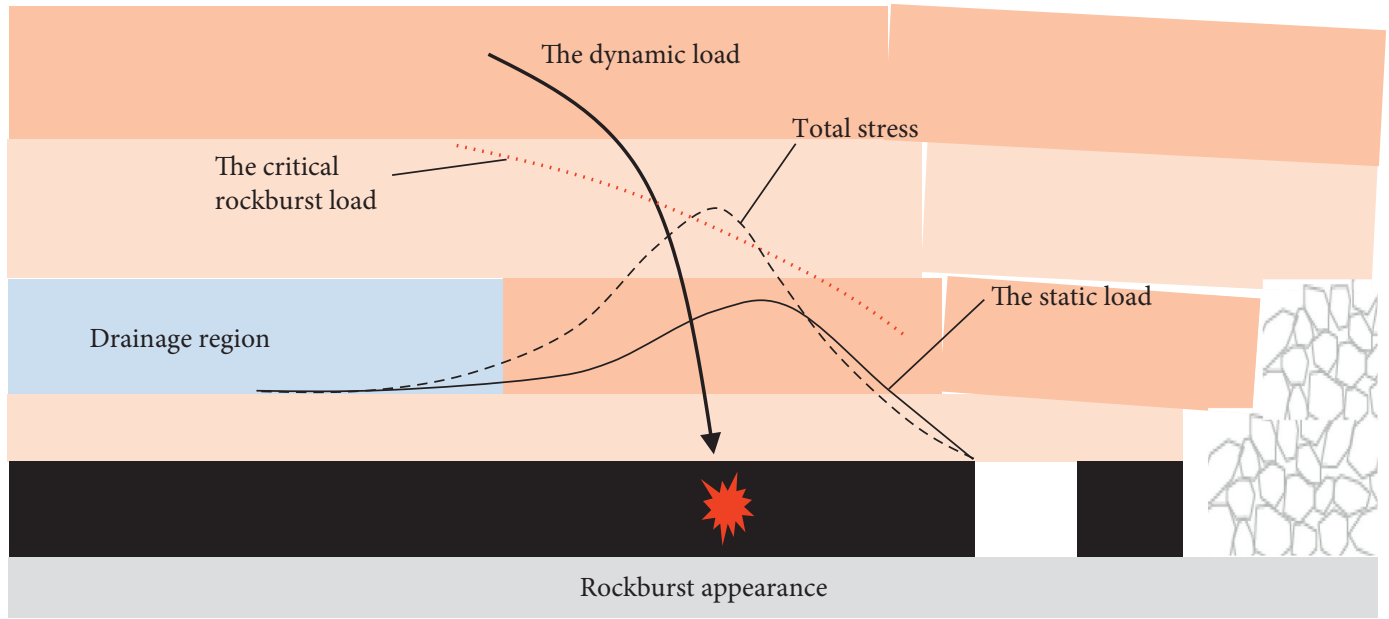

FIgURE 11: Mechanism of rockburst induced by superposition of dynamic and static loads.

The dynamic load in the abnormal mine pressure manifestation region of $1 \#$ spatial island working face is primarily the dynamic load produced during spatial structure formation in the squaring period. Spatial structures are formed by fracturing of high-level rock beams, which produces a dynamic load greater than the first-weighting and periodic-weighting dynamic loads of the working face [28]. In this study, the periodic weighting dynamic load coefficient of the 2202 working face fell within the range of 1.00-1.80. When the dynamic load coefficient in the squaring period was set to 1.80 , the static load stress concentration coefficient required by rockburst induced by superposition of dynamic and static loads would be $=3.27$ / $1.80 \approx 1.81$. Under the combined action of lead abutment pressure, 2201 goaf lateral pressure, drainage boost region, and squaring-induced static load increase, the squaring region was exposed to rockburst induced by the superposition of dynamic and static loads.

\section{Rockburst Control Measures}

According to the force sources for rockbursts identified in the above analysis, a control scheme was prepared, including overall hydraulic fracturing of the external roof of the drainage region, reduction of stoping speed, and pressure relief of large-diameter boreholes. 2202 working face adopts pressure relief measures such as large-diameter drilling and hydraulic fracturing along the goaf. The number and energy of microseismic events increase obviously during the square period. 4 events with energy above 10E5J were detected by microseismic monitoring system (coal stress, drilling cuttings method does not monitor the data exceeding the standard).

6.1. Overall Hydraulic Fracturing of the External Roof of the Drainage Region. In roof hydraulic fracturing, a directional initial crack was made in the roof, and high-pressure water was continuously injected into the crack, in order to propagate the roof crack until it connected with adjacent cracks and damaged roof integrity [36]. The fracture characteristics and 3D fractal fracture of solid-fluid coupling have been studied $[37,38]$.

Rockburst in the drainage region was primarily induced by drainage stress transfer, but the transferred stress remained in the working face and affected the safe stoping of the working face. 1\# spatial island working face formed because the drainage region transferred stress to a more dangerous area. As a result of roof hydraulic fracturing outside the drainage region, the drainage region and the hydraulic fracturing zone formed an overall regular pressure relief protection layer (see Figure 12), which could reduce static loads in the fracturing zone as well as at the drainage boundary and weaken the fracturing dynamic loads of highlevel strata.

6.2. Pressure Relief of Large-Diameter Boreholes (Triaxial Transfer of Stress and Reduction of Static Loads on Roadway Surrounding Rock). In pressure relief of large-diameter boreholes, boreholes distributed at small spacings connected the cracks in coal mass to relieve and transfer coal mass stress. In this way, they modified the mechanical properties of the coal mass and weakened the ability of coal seams to store elastic energy, mitigating rockburst within the coal mass [39].

Large-diameter boreholes formed a pressure relief belt around the roadway and kept coal mass stress away from the roadway (see Figure 13). The comprehensive compressive strength and the critical rockburst load of the deep coal mass were far greater than those of the coal mass near the roadway, mitigating the chance of a rockburst.

6.3. Reduction of Stoping Speed. The aim of reducing stoping speed is to lower lead abutment pressure and reduce the effect of stoping on overburden. Studies have shown that a lower stoping speed leads to smaller peak lead abutment stress and longer distance of peak position from the working face. A low stoping speed can reduce the movement of roof masonry beam structures, lower the level of energy released by their fractures, and weaken the intensity of mine 


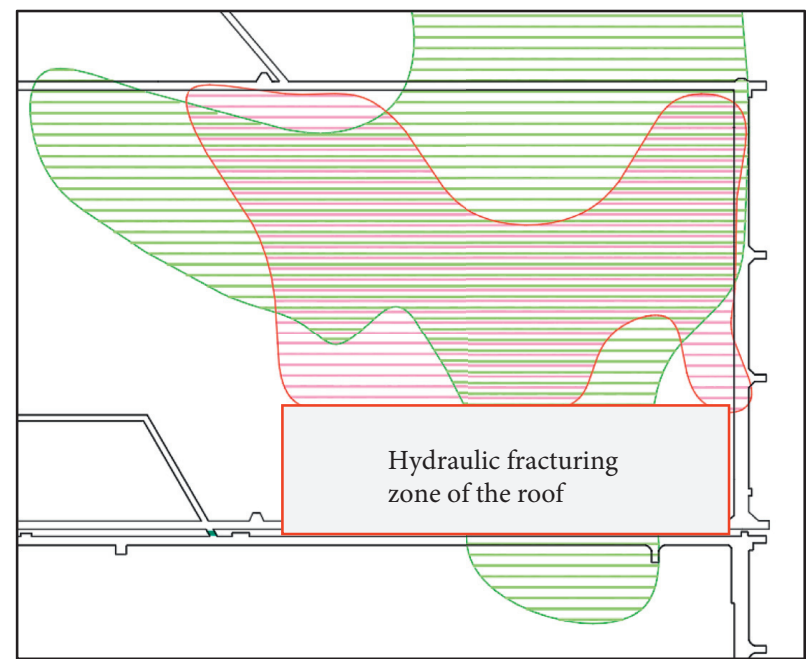

FIGURE 12: Hydraulic fracturing zone of the external roof of the drainage region.

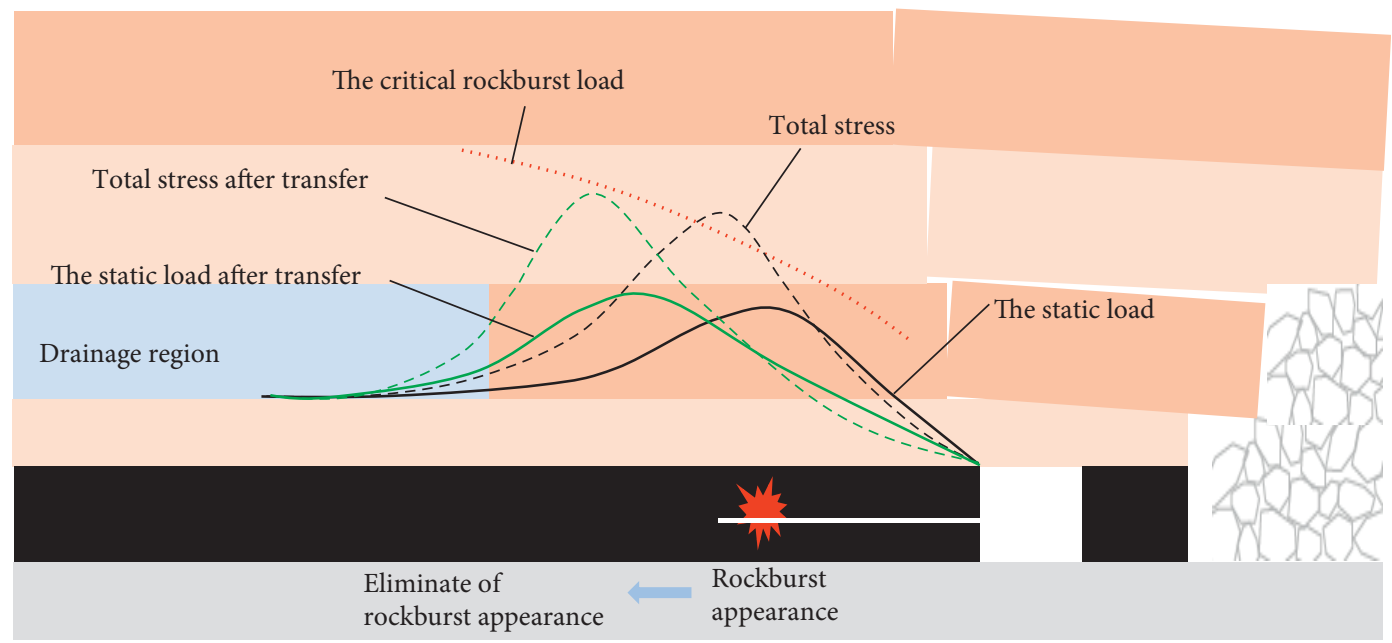

FIGURE 13: Rockburst reduction principle of large-diameter boreholes.

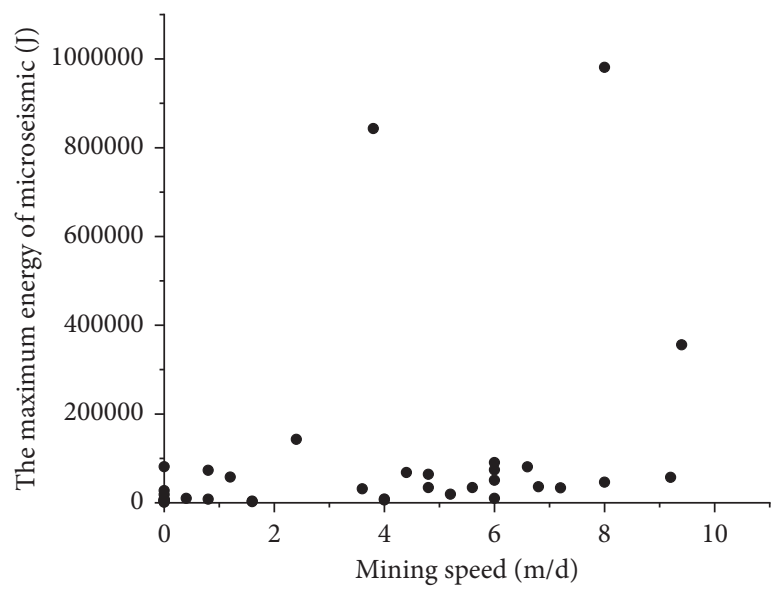

Figure 14: Relationship between mining speed and the microseismic maximum energy.

earthquakes. There is a critical stoping speed under specific stoping conditions. After exceeding the critical stoping speed, microseismic energy and major event frequency both increase significantly with increasing stoping speed. In contrast, before reaching the critical stoping speed, microseismic monitoring data are not responsive to stoping speed [40]. 
In regions facing the rockburst induced by high static loads and dynamic and static loads, properly reducing stoping speed helps to mitigate lead stress concentration on the working face and weaken the intensity of the fracturing dynamic loads of roof strata, thus achieving the goal of rockburst control. In the square period of the working face, the mining speed and the microseismic maximum energy are shown in Figure 14.

The microseismic monitoring system begins to detect large energy events when the mining speed exceeds $3.8 \mathrm{~m}$. This phenomenon verifies the relationship between the mining speed and the intensity of roof movement.

\section{Conclusions}

With regard to the specific conditions of the 2202 working face, this study explored the static-stress spatial islands formed by roof drainage regions and goafs as well as the squaring effect of the working face and analyzed the dynamic and static load mechanism of the rockburst appearance of the gob-side roadway of the 2202 working face from stoping to squaring stage.

The static load evolution process of drainage regions and goafs under different spatial relationships was analyzed to obtain the stress states of various spatial islands. The drainage region of the Yan'an Formation and 2201 goaf formed 1\# spatial island (after initial mining). The average frequency and average energy of $1 \#$ spatial island were 2.04-2.41 times and 1.37-2.04 times of those of other zones, respectively. This result validated the presence of spatial islands in the working face.

Based on the evolution of the roof rectangular plate as well as existing studies on numerical simulation, it was found that the lead abutment stress of the squaring region was 1.2 times of that of the nonsquaring region, and high static loads existed in the coal wall in front of the working face during the squaring period. The microseismic frequency and maximum energy of the squaring region of the 2202 working face were both more than three times of those of the nonsquaring region, so there was a significant squaringinduced dynamic loading effect.

Following the theory of rockburst induced by superposition of dynamic and static loads, this study set the critical stress concentration coefficient for rockburst induced by spatial islands and squaring under high static loads as 3.27 and the critical static-stress concentration coefficient for rockburst induced by dynamic and static loads as 1.81. A control scheme was prepared, including overall hydraulic fracturing of the external roof of the drainage region, reduction of stoping speed, and pressure relief of large-diameter boreholes. The first squaring region was advanced safely on-site. There were no spatial islands in the second squaring region, nor were any rockburst observed.

\section{Data Availability}

The data used to support the findings of this study are available from the corresponding author upon request.

\section{Conflicts of Interest}

The authors declare that there are no conflicts of interest regarding the publication of this paper.

\section{Acknowledgments}

This research was supported by the National Natural Science Foundation for Young Scientists of China (Grant no. 52004004).

\section{References}

[1] L. P. Dai, Y. S. Pan, Z. H. Li et al., "Quantitative mechanism of roadway rockbursts in deep extra-thick coal seams: theory and case histories," Tunnelling and Underground Space Technology Incorporating Trenchless Technology Research, vol. 111, Article ID 103861, 2021.

[2] L. Jiang, P. Kong, P. Zhang et al., "Dynamic analysis of the rock burst potential of a longwall panel intersecting with a fault," Rock Mechanics and Rock Engineering, vol. 53, no. 4, pp. 1737-1754, 2020.

[3] J. W. Liu, C. Y. Liu, Q. L. Yao, and G. Si, "The position of hydraulic fracturing to initiate vertical fractures in hard hanging roof for stress relief," International Journal of Rock Mechanics and Mining Sciences, vol. 132, Article ID 104328, 2020.

[4] S. Q. He, D. Z. Song, X. Q. He et al., "Coupled mechanism of compression and prying-induced rock burst in steeply inclined coal seams and principles for its prevention," Tunnelling and Underground Space Technology, vol. 98, Article ID 103327, 2020.

[5] A. Y. Cao, L. L. Zhu, F. C. Li, M. Dou, Y. L. Zhao, and Z. L. Zhen, "Mechanism of rock burst caused by fracture of key strata during irregular working face mining and its prevention methods," International Journal of Mining Science and Technology, vol. 29, no. 6, pp. 889-897, 2019.

[6] W. Z. Cao, J. Q. Shi, S. Durucan, A. Korre, and S. Jamnikar, "Numerical modelling of anomalous microseismicity influenced by lithological heterogeneity in longwall top coal caving mining," International Journal of Coal Geology, vol. 216, Article ID 103305, 2019.

[7] G. Wang, S. Gong, L. Dou, W. Cai, X. Yuan, and C. Fan, "Rockburst mechanism and control in coal seam with both syncline and hard strata," Safety Science, vol. 115, pp. 320-328, 2019.

[8] H. Wang, R. Shi, C. Lu, Y. Jiang, D. Deng, and D. Zhang, "Investigation of sudden faults instability induced by coal mining," Safety Science, vol. 115, pp. 256-264, 2019.

[9] G. Wang, S. Gong, L. Dou, H. Wang, W. Cai, and A. Cao, "Rockburst characteristics in syncline regions and microseismic precursors based on energy density clouds," Tunnelling and Underground Space Technology, vol. 81, pp. 83-93, 2018.

[10] S. Zhu, Y. Feng, F. Jiang, and J. Liu, "Mechanism and risk assessment of overall-instability-induced rockbursts in deep island longwall panels," International Journal of Rock Mechanics and Mining Sciences, vol. 106, pp. 342-349, 2018.

[11] T.-B. Zhao, W.-Y. Guo, Y.-L. Tan, Y.-C. Yin, L.-S. Cai, and J.-F. Pan, "Case studies of rock bursts under complicated geological conditions during multi-seam mining at a depth of 800 m," Rock Mechanics and Rock Engineering, vol. 51, no. 5, pp. 1539-1564, 2018. 
[12] J. He, L.-M. Dou, Z.-L. Mu, A.-Y. Cao, and S.-Y. Gong, "Numerical simulation study on hard-thick roof inducing rock burst in coal mine," Journal of Central South University, vol. 23, no. 9, pp. 2314-2320, 2016.

[13] A.-Y. Cao, L.-M. Dou, C.-B. Wang, X.-X. Yao, J.-Y. Dong, and $\mathrm{Y}$. Gu, "Microseismic precursory characteristics of rock burst hazard in mining areas near a large residual coal pillar: a case study from Xuzhuang coal mine, Xuzhou, China," Rock Mechanics and Rock Engineering, vol. 49, no. 11, pp. 44074422, 2016.

[14] J.-C. Wang, F.-X. Jiang, X.-J. Meng, X.-Y. Wang, S.-T. Zhu, and Y. Feng, "Mechanism of rock burst occurrence in specially thick coal seam with rock parting," Rock Mechanics and Rock Engineering, vol. 49, no. 5, pp. 1953-1965, 2016.

[15] A. Y. Cao, L. L. Zhu, and F. C. Li, "Characteristics of "T" type overburden structure and dynamic pressure evolution in isolated island working face under thick and hard rock strata," Journal of China Coal Society, vol. 39, no. 2, pp. 328-335, 2014.

[16] F. X. Jiang, X. C. Qu, X. H. Ni, F. Q. Wang, and Z. B. Tang, "Case study on the mine earthquake caused by hard rock fracture in Baodian coal mine," Journal of China Coal Society, vol. 38, no. S2, pp. 319-324, 2013.

[17] W. L. Yang, Q. D. Wei, X. C. Qu, W. X. Liu, and J. N. Zhang, "Research on classification and application of isolated island working face based on burst prevention," Journal of Safety Science and Technology, vol. 14, no. 12, pp. 107-113, 2018.

[18] A. Y. Cao, C. B. Wang, L. M. Dou, Y. Gu, Y. Li, and J. Dong, "Dynamic manifestation mechanism of mining on the island coalface along fault and dynamic pre-warning of seismic waves with seismic tomography," Journal of Mining and Safety Engineering, vol. 34, no. 3, pp. 411-417, 2017.

[19] S. T. Zhu, F. X. Jiang, J. H. Liu et al., "Types, occurence mechanism and prevention of overall istability induced rockbursts in China coal mines," Journal of China Coal Society, vol. 45, no. 11, pp. 3667-3677, 2020.

[20] S. J. Wang, K. J. Huang, and S. Y. Jin, "Feasibility analysis of the recovery of "Island-like" working face," Coal Science and Technology, pp. 1-7, 2020, http://kns.cnki.net/kcms/detail/11. 2402.td.20200206.1847.040.html.

[21] D. C. Wang, Q. Wang, S. C. Li et al., "Stress distribution characteristics of deep mine in fully-mechanized sublevel caving face based on microseismic and online stress monitoring system," Journal of Mining and Safety Engineering, vol. 32, no. 3, pp. 382-388, 2015.

[22] F. L. He, D. D. Chen, and S. R. Xie, "The kDL effect on the first fracture of main roof with elastic foundation boundary," Chinese Journal of Rock Mechanics and Engineering, vol. 36, no. 6, pp. 1384-1399, 2017.

[23] F. L. He, W. R. He, D. D. Chen, S. R. Xie, H. Li, and C. X. He, "First fracture structure characteristics of main roof plate considering elastic-plastic deformation of coal," Journal of China Coal Society, vol. 45, no. 8, pp. 2704-2717, 2020.

[24] X. F. Wang and M. Z. Gao, "Mechanical model of fracture mechanism of stope roof for working face with variable length," Journal of China University of Mining and Technology, vol. 44, no. 1, pp. 36-45, 2015.

[25] W. L. Zhang, X. C. Qu, C. Li et al., "Fracture analysis of multihard roofs based on microseismic monitoring and control techniques for induced rock burst: a case study," Arabian Journal of Geosciences, vol. 12, no. 24, p. 784, 2019.

[26] D. Li, F. X. Jiang, C. W. Wang, Z. Tian, and Y. Wang, "Study on the mechanism and prevention technology of "square position" and "stress breakdown effect" inducing rockburst,"
Journal of Mining and Safety Engineering, vol. 35, no. 5, pp. 1014-1021, 2018.

[27] L. H. Kong, Q. X. Qi, F. X. Jiang, and Z. Ouyang, “Abnormal strata stress resulted from goaf square of longwall face based on microseismic monitoring," Chinese Journal of Rock Mechanics and Engineering, vol. 31, no. S2, pp. 3889-3896, 2012.

[28] C. W. Wang, F. X. Jiang, Q. G. Sun et al., "The forecasting method of rockburst and the application based on overlying multistate spatial structure theory," Journal of China Coal Society, vol. 34, no. 2, pp. 150-155, 2009.

[29] F. X. Jiang, G. Cheng, Y. Feng, C. Wang, and Y. Xu, "Research on coal overall instability of isolated working face with irregular gobs on both sides," Chinese Journal of Rock Mechanics and Engineering, vol. 34, no. S2, pp. 4164-4170, 2015.

[30] G. A. Wang, S. T. Zhu, F. X. Jiang et al., "Mechanism of rock burst induced by overall instability of isolated coal and its prevention in large well at thousands-kilometer underground," Journal of Mining \& Safety Engineering, vol. 36, no. 5, pp. 968-967, 2019.

[31] Z.-L. Li, L.-M. Dou, G.-F. Wang, W. Cai, J. He, and Y.-L. Ding, "Risk evaluation of rock burst through theory of static and dynamic stresses superposition," Journal of Central South University, vol. 22, no. 2, pp. 676-683, 2015.

[32] L. M. Dou, J. He, A. Y. Cao, S. Y. Gong, and W. Cai, "Rock burst prevention methods based on theory of dynamic and static combined load induced in coal mine," Journal of China Coal Society, vol. 40, no. 7, pp. 1469-1476, 2015.

[33] W. Cai, X. X. Bai, G. Y. Si, W. Cao, S. Gong, and L. Dou, “A monitoring investigation into rock burst mechanism based on the coupled theory of static and dynamic stresses," Rock Mechanics and Rock Engineering, vol. 53, no. 12, pp. 54515471, 2020.

[34] J. He, L. Dou, S. Gong, J. Li, and Z. Ma, "Rock burst assessment and prediction by dynamic and static stress analysis based on micro-seismic monitoring," International Journal of Rock Mechanics and Mining Sciences, vol. 93, pp. 46-53, 2017.

[35] J. Z. Yang and K. G. Zheng, "The mechanism of overburden dynamic disasters and its control technology in top-coal caving in the mining of thick coal seams," Journal of Mining \& Safety Engineering, vol. 37, no. 4, pp. 750-758, 2020.

[36] H. Kang, H. Lv, F. Gao, X. Meng, and Y. Feng, "Understanding mechanisms of destressing mining-induced stresses using hydraulic fracturing," International Journal of Coal Geology, vol. 196, pp. 19-28, 2018.

[37] J. Liu, Y. Xue, Q. Zhang, H. Wang, and S. Wang, "Coupled thermo-hydro-mechanical modelling for geothermal doublet system with 3D fractal fracture," Applied Thermal Engineering, vol. 200, Article ID 117716, 2022.

[38] Y. Xue, J. Liu, P. G. Ranjith, X. Liang, and S. Wang, "Investigation of the influence of gas fracturing on fracturing characteristics of coal mass and gas extraction efficiency based on a multi-physical field model," Journal of Petroleum Science and Engineering, vol. 206, Article ID 109018, 2021.

[39] S. Zhang, Y. Li, B. Shen, X. Sun, and L. Gao, "Effective evaluation of pressure relief drilling for reducing rock bursts and its application in underground coal mines," International Journal of Rock Mechanics and Mining Sciences, vol. 114, pp. 7-16, 2019.

[40] L. F. Feng, L. M. Dou, X. D. Wang et al., "Mechanism of mining advance speed on energy release from hard roof movement," Journal of China Coal Society, vol. 44, no. 11, pp. 3329-3339, 2019. 